\title{
Type 2 innate lymphoid cells participate in IL-33-stimulated Th2-associated immune response in chronic obstructive pulmonary disease
}

\author{
MIN JIANG ${ }^{1}$, SIMIN TAO ${ }^{1}$, SHAOHUA ZHANG ${ }^{1}$, JING WANG $^{1}$, \\ FENGBO ZHANG ${ }^{2}$, FENGSEN LI ${ }^{1}$ and JIANBING DING ${ }^{3}$
}

\begin{abstract}
${ }^{1}$ National Traditional Chinese Medicine Clinical Research Base, Traditional Chinese Medicine Hospital Affiliated
to Xinjiang Medical University, Xinjiang Laboratory of Respiratory Disease Research, Urumqi, Xinjiang 830011;

${ }^{2}$ Department of Clinical Laboratory, The First Affiliated Hospital of Xinjiang Medical University, Urumqi, Xinjiang 830054;

${ }^{3}$ Department of Immunology, College of Basic Medicine, Xinjiang Medical University, Urumqi, Xinjiang 830011, P.R. China
\end{abstract}

Received October 30, 2018; Accepted March 15, 2019

DOI: 10.3892/etm.2019.7924

\begin{abstract}
The aim of the present study was to investigate the roles of type 2 innate lymphoid cells (ILC2s) and interleukin-33 (IL-33) in chronic obstructive pulmonary disease (COPD). Serum and peripheral blood mononuclear cells (PBMCs) were isolated from healthy controls and COPD patients. ILC2 cells from the peripheral blood of COPD patients were stimulated with IL-33 or neutralizing ST2 antibody+IL-33 in vitro. The cell viability was assessed using a Cell Counting Kit- 8 assay. ELISA was used to detect serum IL-33 and the levels of IL-4, IL-5, IL-6, IL-13 and soluble ST2 (sST2) in the culture supernatant. The percentage of ILC2 cells was measured by flow cytometry. The mRNA expression levels of GATA binding protein 3 (GATA3), RAR-related orphan receptor (ROR) $\alpha$, ST2 and prostaglandin D2 receptor 2 (CRTH2) were detected by reverse transcription-quantitative PCR. It was revealed that IL-33, IL-5, IL-6 and IL-13 were significantly elevated in peripheral blood of patients with COPD. The proportion of ILC2s in peripheral blood of COPD patients was significantly increased, and the expression of RORA and CRTH2 was increased. The proportion of ST2+ ILC2 cells was significantly increased. After $48 \mathrm{~h}$ of IL-33 stimulation in vitro, the ratio of
\end{abstract}

Correspondence to: Professor Jianbing Ding, Department of Immunology, College of Basic Medicine, Xinjiang Medical University, 4 Xinyi Road, Xinshi, Urumqi, Xinjiang 830011, P.R. China

E-mail: 1601379937@qq.com

Professor Fengsen Li, National Traditional Chinese Medicine Clinical Research Base, Traditional Chinese Medicine Hospital Affiliated to Xinjiang Medical University, Xinjiang Laboratory of Respiratory Disease Research, 116 Huanghe Road, Shayibake, Urumqi, Xinjiang 830011, P.R. China

E-mail: fengsen602@163.com

Key words: chronic obstructive pulmonary disease, interleukin-33, type 2 innate lymphoid cells linage $\mathrm{CD}^{-} 5^{+} \mathrm{CD} 127^{+} \mathrm{CRTH} 2^{+}$cells reached a maximum. In addition, the viability of ILC2 cells, the expression levels of RORA, GATA3, ST2 and CRTH2 mRNA and the cytokines IL-4, IL-6, IL-5, IL-13 and sST2 were significantly increased. These effects were abrogated by treatment with anti-ST2. In conclusion, IL-33 is upregulated in the serum of patients with COPD and the proportion of ILC2s among the PBMCs is increased. IL-33 may promote the proliferation of ILC2 cells and secrete type 2 T-helper cell cytokines to participate in the immune response in COPD.

\section{Introduction}

The worldwide prevalence of chronic obstructive pulmonary disease (COPD) and associated mortality have been increasing (1). According to the Global Disease Burden Research Project and the World Health Organization, COPD will become the third largest cause of death in the world and the fifth largest economic burden in the world by 2020 (2). COPD is a universally preventable and treatable disease characterized by persistent airflow limitation, and is usually associated with progressive development and an increase in the chronic inflammatory response in the respiratory tract, including the lung (3). Bronchoscopy reveals infiltration of neutrophils, lymphocytes and macrophages in the airways of affected patients (4). These inflammatory cells produce multiple immune mediators (5). A large number of studies have indicated that the immune response has an important role in the pathogenesis of COPD $(4,6,7)$. Adaptive immunity, and particularly innate immunity, may be involved in the abnormal inflammatory response and tissue damage during COPD.

Interleukin (IL)-33 is a member of the IL-1 cytokine family and may bind with the heterodimeric receptor composed of ST2 [also known as IL-33 receptor (IL-33R) or IL1R-like 1] and IL-1R-combined protein (IL-1RAcP) to induce multiple immune responses (8). The IL-33/ST2 signaling pathway is involved in various inflammatory diseases, including asthma, influenza-associated airway hyper responsiveness and allergic rhinitis (9-11). In addition, IL-33 has an important role in the 
development of COPD (4). Kearley et al (12) indicated that cigarette smoke may cause changes in the lung microenvironment and promote IL-33-dependent inflammatory responses, resulting in exacerbations of COPD. IL-33 is highly expressed in the lung tissue of patients with severe COPD and is associated with IL-13 and airway mucin expression, which in turn causes COPD (12). In addition, bronchial epithelial cell-derived IL-33 is involved in regulating the innate immune response of COPD through IL-13 (13), causing airway mucus secretion and airway hyper reactivity $(14,15)$. The receptor ST2 is highly expressed on dendritic cells, natural killer $\mathrm{T}$ cells, innate lymphocytes and basophils, but not on naïve $\mathrm{CD} 4^{+} \mathrm{T}$ cells (16). To date, it has remained elusive how epithelial-derived IL-33 induces innate immune cells to produce type 2 T-helper (Th2) cell cytokines, and thus participate in the disease process of COPD.

Type 2 innate lymphoid cells (ILC2s) are one of the major types of Th2 cell of the innate immune system (17). ILC2s were once known as natural helper cells (18), nuocytes (19), or Ih 2 cells (20). The development of ILC2 relies on the transcription factor RORA (21) and the differentiation of ILC2 depends on inhibitor of DNA binding 2 and GATA binding protein 3 (GATA3). ILC2s are mainly distributed in the intestinal mucosa, blood, lungs and airway mucosa of humans and mice (22). ILC2s exhibit morphological features of lymphocytes, but do not express lineage (Lin) markers or antigen heterologous receptors (T-cell receptor or B-cell receptor) (23). The molecules on the surface of ILC2 mainly include CD45, IL-7R $\alpha$ (CD127), prostaglandin D2 receptor 2 (CRTH2), T1/ST2, IL-17RB, CD25, CD38 and CD69 (24). Although certain studies have described the important role of ILC2 in helminth infections, respiratory inflammatory responses and atopic dermatitis (18-20), the function of ILC2 in COPD has remained to be fully investigated (25).

It has been indicated that IL-33 is the major predisposing factor for human ILC2s (17). IL-33 may induce ILC2 to produce IL-4, IL-5, IL-10 and IL-13 to participate in Th2-type immune responses (26). However, the biological role of peripheral blood ILC2s and IL-33 in patients with COPD has remained elusive.

In the present study, the proportion and characteristics of ILC2s in peripheral blood of patients with COPD were examined. The results indicated that the expression of GATA3 and ST2 in ILC2s cells was significantly increased. Further in vitro experiments suggested that IL-33 induced the release of a large number of Th2 cytokines from ILC2. Therefore, IL-33 and ILC2s have a role in the regulation of COPD inflammation and may be potential therapeutic targets for COPD.

\section{Materials and methods}

Patients. In total, 107 patients with COPD and 110 matched control subjects were recruited (Table I) from January 2017 to September 2018 at the Traditional Chinese Medicine Hospital Affiliated to Xinjiang Medical University. COPD patients were diagnosed according to the criteria proposed by the Global Initiative for Chronic Obstructive Lung Disease (GOLD) guidelines (1) and were free of exacerbation for at least 4 weeks prior to the study. Healthy control subjects were age and sex matched who visited the hospital for routine physical examination. Patients with COPD and controls all had a history of smoking with a pack-year index of $>20$. Inclusion criteria for COPD were as follows: i) Patients with COPD diagnosed based on clinical manifestations (e.g., chronic cough, cough and/or dyspnea), history of exposure to risk factors, physical signs and pulmonary function tests; ii) patients with incomplete reversible airflow limitation (forced expiratory volume in one second/forced vital capacity $<70 \%$ after administration of bronchodilator). The exclusion criteria were as follows: i) Comorbidities of severe lung diseases, including pneumothorax, lung cancer and pulmonary tuberculosis; ii) intake of inhaled corticosteroids or oral theophylline, anti-inflammatory therapy or oral steroids for chronic inflammatory diseases during the previous 4 weeks; iii) patients with primary diseases, including severe cardiovascular diseases, hepatorenal diseases and hematopoietic system diseases; iv) pregnant and lactating females. Peripheral blood was obtained from all the subjects.

Reagents. The anti-human antibodies included FITC-labeled CD3 (cat. no. 561807), CD19 (cat. no. 555412), CD123 (cat.no.561694),CD11b (cat.no.562793),CD11c (cat.no.561355), CD8 (cat. no. 557085), FceR1 (cat. no. 12-5899-41; Thermo Fisher Scientific, Inc.), CD14 (cat. no. 555397), CD4 (cat. no. 561005), CD56 (cat. no. 562794); APC-CY7 labeled CD45 (cat. no. 557748); PerCP-CY5.5 labeled CRTH2 (cat. no. 558042); and PE-CY7 labeled IL-7R $\alpha$ (cat. no. 557938) and IL-13 (cat. no. JES10-5A2; all from BD Bioscience, except FceR1). IL-33 (cat. no. EK133), IL-4 (cat. no. EK1042), IL-5 (cat. no.EK1052), IL-6 (cat. no. EK1062),IL-13 (cat. no.EK1132) and sST2 (cat. no. EK11634) ELISA kits were purchased from Hangzhou Lianke Biotechnology Co., Ltd. The EasySep ${ }^{\mathrm{TM}}$ Human ILC2 Isolation kit was purchased from STEMCELL ${ }^{\mathrm{TM}}$ Technologies (cat. no. 17972; Vancouver, British Columbia, Canada). Iscove's modified Dulbecco's medium (IMDM; cat. no. 12440061) was from Thermo Fisher Scientific, Inc. Penicillin-streptomycin was from Gibco (Thermo Fisher Scientific, Inc.). Human IL-2 was from Peprotech. Human recombinant (r)IL-33 cytokine (cat. no. 3625-IL-010), human ST2/IL-33R neutralizing antibody (cat. no. MAB523) and normal goat IgG control (cat. no. AB-108-C) were purchased from R\&D Systems. A Cell Counting Kit-8 was purchased from Dongren Chemical Technology Co., Ltd. (Dojindo Laboratories). TRIzol LS reagent was from Invitrogen (Thermo Fisher Scientific, Inc.). The Transcriptor first strand complementary (c)DNA synthesis kit was from Roche Diagnostics (cat. no. 4379012001; Roche Diagnostics). Ficoll-Hypaque Solution (cat. no. P8610) was obtained from Beijing Solarbio Science \& Technology Co., Ltd.

Flow cytometry, cell sorting and cell culture. Peripheral blood mononuclear cells (PBMCs) were isolated from whole blood using the Ficoll density gradient method. Samples were diluted with PBS at 1:1 ratio, mixed with equal volumes of Ficoll-Hypaque Solution and centrifuged at $750 \mathrm{x}$ g for $22 \mathrm{~min}$ at room temperature. The white supernatant consisted of PBMCs. PBMCs were then rinsed twice with PBS and then centrifuged at $500 \mathrm{x} \mathrm{g}$ for $10 \mathrm{~min}$ at room temperature to collect the cell pellets. Then the cells were re-suspended in PBS to yield a cell concentration of $1 \times 10^{6}$ cells $/ \mathrm{ml}$. The antibodies, including Lin-(CD3, CD19, CD123, CD11b, CD11c, CD8, FceR1, CD14, CD4, CD56)-FITC, CD45-APC-CY7, 
Table I. Demographics and clinical characteristics of the study cohort.

\begin{tabular}{lccc}
\hline Variable & Control $(\mathrm{n}=110)$ & COPD (n=107) & P-value \\
\hline Age (years) & $67 \pm 8.9$ & $67 \pm 8.3$ & 0.64 \\
Sex (male/female) & $79 / 31$ & $83 / 24$ & 0.53 \\
Smoking index (pack years) & $30.46 \pm 16.91$ & $31.05 \pm 17.57$ & 0.67 \\
FEV1 (\% predicted) & $78.5 \pm 14.2$ & $58.3 \pm 21.3^{\mathrm{a}}$ & $<6.4 \pm 10.0$ \\
FEV1/FVC (\%) & $80.2 \pm 11.2$ & $5(4.6)$ \\
GOLD grade n (\%) & & $94(87.8)$ \\
Grade I & $94(85.5)$ & $8(7.4)$ \\
Grade II & $16(14.5)$ & 0 \\
Grade III & 0 & $<0.01$ \\
Grade IV & 0 & $<0.01$ \\
\hline
\end{tabular}

${ }^{a} \mathrm{P}<0.01$ vs. Control group. Values are expressed as the mean \pm standard deviation. COPD, chronic obstructive pulmonary disease; FEV1, forced expiratory volume in one second; FVC, forced vital capacity; GOLD, Global Initiative for Chronic Obstructive Lung Disease.

PerCP-CY5.5-CRTH2, CD127-PE-CY7 and ST2-APC, were added, followed by incubation at room temperature for $30 \mathrm{~min}$ in the dark. Isotype control was added to reduce non-specific binding. The cells were washed with PBS twice. Samples were detected by flow cytometry (LSR II; BD Bioscience), and analyzed using FlowJo software version 7.6 (FlowJo, LLC).

As the percentage of ILC2 in peripheral blood was low, the ILC2 cells were separated from the mixed blood of 5-6 subjects (total volume, $200 \mathrm{ml}$ ) and a total of $10 \mathrm{mixed}$ blood samples were used. ILC2 cells were identified as $\mathrm{Lin}^{-} \mathrm{CD} 45^{+} \mathrm{CD} 127^{+}(\mathrm{IL7R} \alpha)$, and $\mathrm{CRTH} 2^{+}$and $\mathrm{ST} 2^{+}$cells were identified as $\mathrm{Lin}^{-} \mathrm{CD} 45^{+} \mathrm{CD} 127^{+}(\mathrm{IL} 7 \mathrm{R} \alpha) \mathrm{CRTH} 2^{+} \mathrm{ST} 2^{+}$. The isolation of ILC2 cells from the mixed peripheral blood of COPD patients was performed using the human ILC2 isolation kit according to the manufacturer's protocol. ILC2 cells were then seeded into 96 -well plates at 500 cells/well, mixed with gamma-irradiated PBMCs (24) from three healthy volunteers $\left(2 \times 10^{6}\right.$ cells $\left./ \mathrm{ml}\right)$, and cultured in the presence of $500 \mathrm{ng} / \mathrm{ml}$ IL-2 in IMDM (Thermo Fisher Scientific, Inc.) supplemented with $10 \%$ fetal bovine serum (Sigma-Aldrich; Merck KGaA) and $10 \mathrm{ml} / 1$ penicillin-streptomycin.

Cell stimulation. After 4-6 weeks, the growing ILC2 cells were seeded into 24 -well plates at $1 \times 10^{4}$ cells/well and divided into a control group, an IL-33 stimulation group and an anti-ST-2 neutralization group. Cells in the control group were treated with PBS. Cells in the IL-33 stimulation group were stimulated with human rIL-33 (10, 50 or $100 \mathrm{ng} / \mathrm{ml})$ for $48 \mathrm{~h}$. In the anti-ST-2 neutralization group, cells were pre-treated with human ST2/IL-33R neutralizing antibody $(1 \mu \mathrm{g} / \mathrm{ml})$ or normal goat $\mathrm{IgG}$ control $(20 \mu \mathrm{g} / \mathrm{ml})$ for $1 \mathrm{~h}$ and then treated with human rIL-33 $(10,50$ or $100 \mathrm{ng} / \mathrm{ml})$ for $48 \mathrm{~h}$. The culture supernatants were stored at $-20^{\circ} \mathrm{C}$ for analysis by ELISA.

Measurement of cytokines by ELISA. The concentration of IL-33, IL-4, IL-5, IL-6 and IL-13 in serum and the concentration of IL-4, IL-5, IL-6, IL-13 and soluble (s)ST2 in cell culture supernatant were determined by ELISA using human ELISA kits, according to the manufacturer's instructions. The limits of detection for the IL-33, IL-4, IL-5, IL-6, IL-13 and sST2 ELISA kits were $2.17,0.11,0.76,0.90$ and $1.10 \mathrm{pg} / \mathrm{ml}$, respectively.

Reverse transcription-quantitative $(R T-q) P C R$. Total RNA was extracted from PBMCs of the control group, COPD groups and in vitro-stimulated ILC2 cells using TRIzol LS. Furthermore, the cDNA was synthesized from the isolated total RNA using a Transcriptor first strand cDNA synthesis kit. The mRNA expression levels of CRTH2, GATA3, ST2 and RAR-related orphan receptor (ROR) $\alpha$ were detected using qPCR. Real-time PCR was performed in a BIO-RAD CFX96 detection system (Bio-Rad Laboratories) with SYBR Premix Ex Taq (Takara Bio, Inc.). The PCR parameters were $95^{\circ} \mathrm{C}$ for $5 \mathrm{~min}$, followed by 40 cycles of $95^{\circ} \mathrm{C}$ for $30 \mathrm{sec}$ and $60^{\circ} \mathrm{C}$ for $30 \mathrm{sec}$. Quantitative results were determined using the $2^{-\Delta \Delta \mathrm{Cq}}$ method (27) and gene expression levels were presented as the relative abundance level after normalizing to the mRNA expression levels of GAPDH. The primers used for PCR are listed in Table II.

CCK- 8 assay. Cell viability was detected by Cell Counting Kit-8. In brief, $10 \mu \mathrm{l}$ CCK8 reagent was added to $100 \mu \mathrm{l}$ cell suspension at $1 \mathrm{~h}$ prior to the end of the culture. The absorbance was measured at $450 \mathrm{~nm}$ by using a spectrophotometer.

Statistical analysis. Values are expressed as the mean \pm standard deviation unless otherwise specified. Differences between groups were assessed using an unpaired Student's t-test. One-way analysis of variance were used for comparisons among groups followed by Tukey's test. $\mathrm{P}<0.05$ was considered to indicate statistical significance. All data were analyzed with GraphPad Prism software version 5.0 (GraphPad Software Inc.).

\section{Results}

IL-33 and ST2 are involved in the immune response in COPD. A summary of patient demographics are presented in Table I. No significant differences were identified in the baseline 
Table II. Primers for PCR.

\begin{tabular}{|c|c|c|c|c|c|}
\hline \multirow[b]{2}{*}{ Gene } & \multirow{2}{*}{$\begin{array}{c}\text { Genbank } \\
\text { accession no. }\end{array}$} & \multicolumn{2}{|c|}{ Primer sequence $\left(5^{\prime} \rightarrow 3^{\prime}\right)$} & \multirow{2}{*}{$\begin{array}{l}\text { Product } \\
\text { size (bp) }\end{array}$} & \multirow{2}{*}{$\operatorname{Tm}\left({ }^{\circ} \mathrm{C}\right)$} \\
\hline & & Forward & Reverse & & \\
\hline CRTH2 & NM_004778.2 & CGCCACACTGAAGCCACTCTG & GCGTGGTCGATGTAGCGGATG & 90 & 60 \\
\hline RORA & NM_002943.3 & CTGGTGTGCATAGCGGAGGTTG & CCTGCGGACTGGCAATAATCGG & 101 & 60 \\
\hline GATA3 & NM_001002295.1 & GTGCATGACTCACTGGAGGACTTC & CATGTGGCTGGAGTGGCTGAAG & 114 & 60 \\
\hline ST2 & NM_001282408.1 & CTTCACGGTCAAGGATGAGCAAGG & CACAGGACGGCAGCCAAGAAC & 156 & 60 \\
\hline GAPDH & NM_002046 & CAGGAGGCATTGCTGATGAT & GAAGGCTGGGGCTCATTT & 138 & 60 \\
\hline
\end{tabular}

GATA3, GATA binding protein 3; RORA, RAR-related orphan receptor $\alpha$; CRTH2, ST2 and prostaglandin D2 receptor 2; Tm, melting temperature
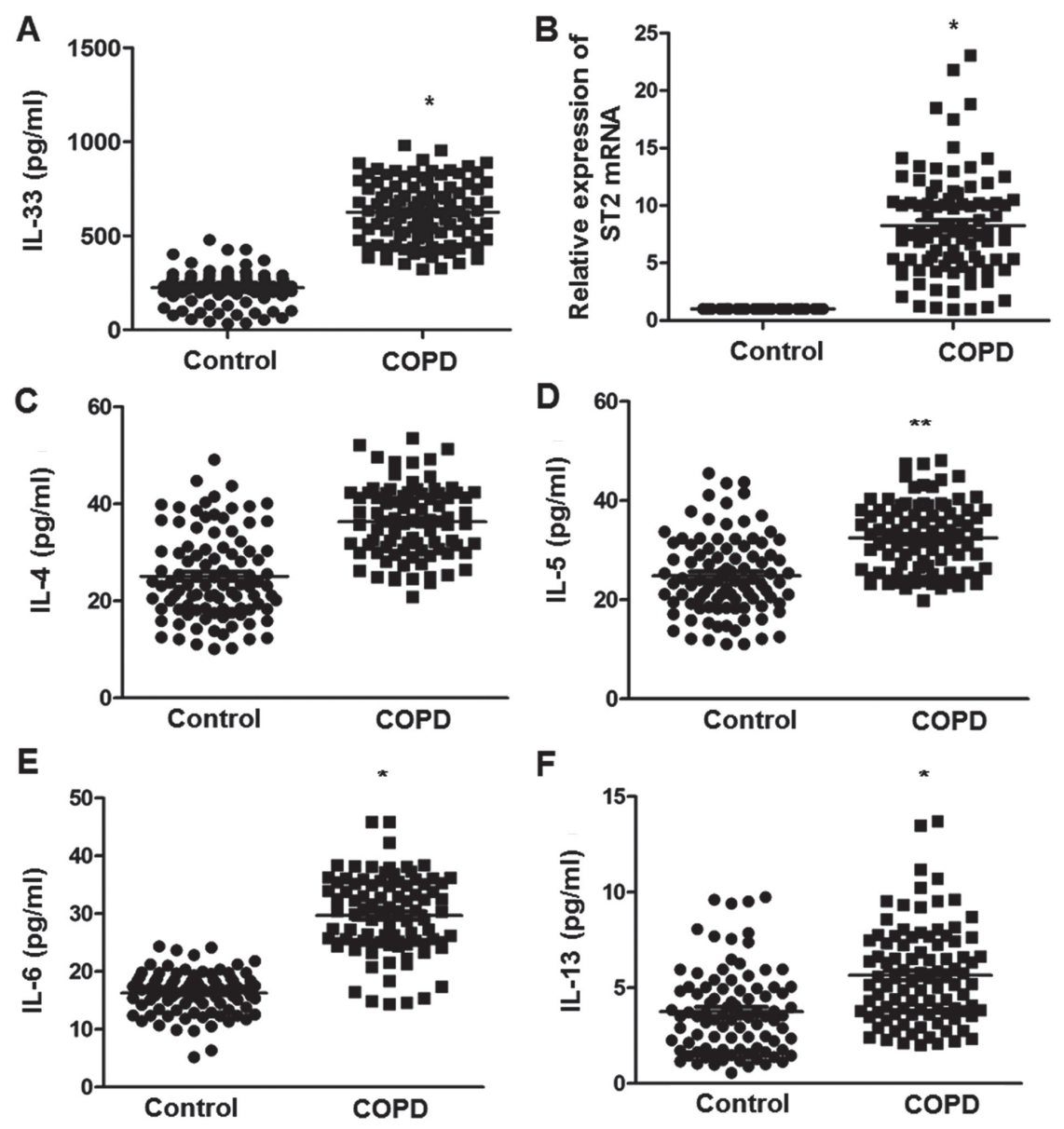

Figure 1. Serum levels of IL-33 and type 2 T-helper cell-associated cytokines in patients with COPD. (A) Serum IL-33 levels in control and COPD patients. (B) Relative expression of IL-33 receptor ST2 mRNA in peripheral blood mononuclear cells. Data were normalized to the control group. (C-F) Serum levels of (C) IL-4, (D) IL-5, (E) IL-6 and (F) IL-13 in control and COPD patients. Values are expressed as the mean \pm standard deviation. ${ }^{*} \mathrm{P}<0.05,{ }^{* *} \mathrm{P}<0.01$ vs. control group. IL, interleukin; COPD, chronic obstructive pulmonary disease.

demographic characteristics of the two groups. Forced expiratory volume (FEV1) and FEV1/forced vital capacity of COPD patients were significantly lower than those in controls. In COPD patients, pulmonary function deteriorated significantly compared with controls. The serum IL-33 levels were assessed in control and COPD patients by using ELISA. The serum levels of IL-33 in COPD patients were significantly higher than those in the control group (Fig. 1A). The expression of
ST2 mRNA detected by RT-qPCR in PBMCs of patients with COPD was also significantly higher than that in the control group (Fig. 1B). In addition, the levels of the cytokines IL-4, IL-5, IL-6 and IL-13 in the serum of the control and COPD subjects were determined. No significant difference was identified in the serum IL-4 levels between the two groups (Fig. 1C). The levels of IL-5, IL-6 and IL-13 in COPD patients were significantly higher than those in the control group (Fig. 1D-F). 
A

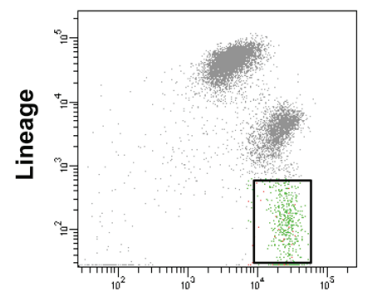

CD45

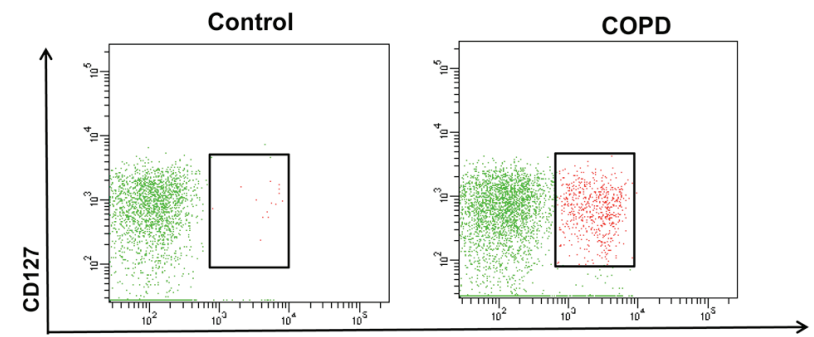

CRTH2
B

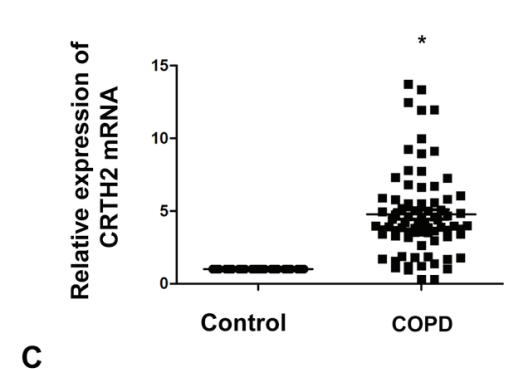

C

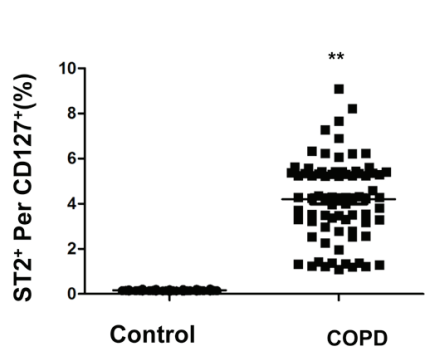

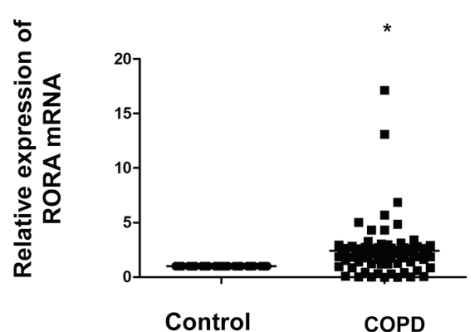
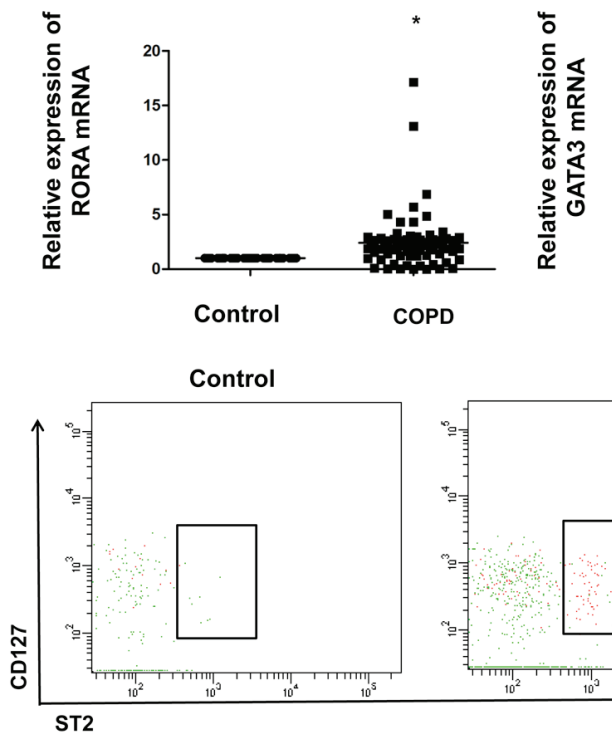
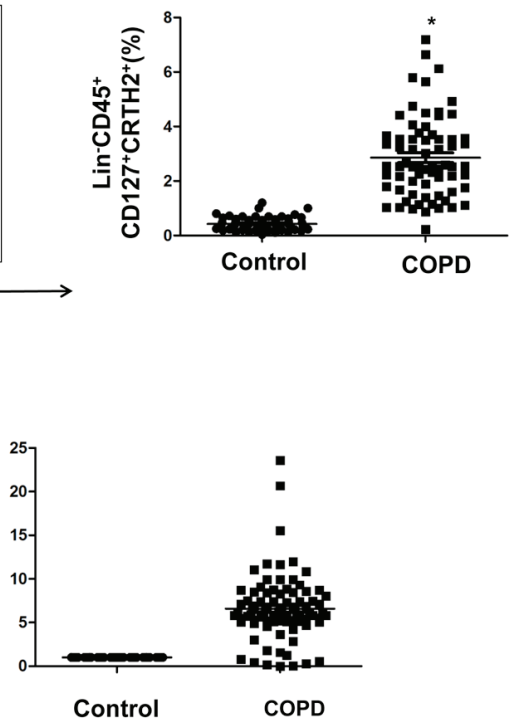

COPD

Figure 2. Increased proportion of ILC2 cells, nuclear transcription factor and ST2 expression in PBMCs of COPD patients. (A) Percentage of ILC2s in the peripheral blood of control subjects and COPD patients. (B) Relative mRNA expression of CRTH2, RORA and GATA3 in PBMCs of control subjects and COPD patients. Data were normalized to the control group and the mean value was set as 1. (C) ST2 expression on the surface of peripheral blood ILC2s from control subjects and COPD patients. Values are expressed as the mean \pm standard deviation. ${ }^{*} \mathrm{P}<0.05,{ }^{* *} \mathrm{P}<0.01$ vs. control group. PBMCs, peripheral blood mononuclear cells; COPD, chronic obstructive pulmonary disease; ILC2s, type 2 innate lymphoid cells; Lin, lineage; GATA3, GATA binding protein 3; RORA, RAR-related orphan receptor $\alpha$; CRTH2, ST2 and prostaglandin D2 receptor 2.

These results indicate that IL-33, ST2 and associated cytokines may be involved in the immune response in COPD.

Peripheral blood ILC2 are significantly increased in COPD patients. In the present study, $\mathrm{Lin}^{-\mathrm{CD}} 45^{+} \mathrm{CD} 127^{+} \mathrm{CRTH} 2^{+}$cells were detected in peripheral blood by using flow cytometry, and the changes in the percentage of ILC2 cells in peripheral blood of control and COPD subjects were analyzed to determine whether they are involved in the pathogenesis of COPD. The results indicated that the proportion of ILC2 cells in the peripheral blood of COPD patients was significantly higher than that in the control group (Fig. 2A). Furthermore, RT-qPCR was used to detect the mRNA expression levels of transcription factors in PBMCs of control and COPD subjects. The results indicated that the relative mRNA expression levels of CRTH2 and RORA in PBMCs of COPD patients were significantly higher than those in the controls $(\mathrm{P}<0.05$; Fig. $2 \mathrm{~B})$. The expression of ST2 on the surface of ILC2 cells was then determined using flow cytometry. As presented in Fig. 2C, a high expression of ST2 on the surface of ILC2 cells was identified in COPD patients, which was significantly higher than that in the control group. The above results indicate that ILC2s accounted for a large proportion of PBMCs in COPD patients, suggesting a role of ILC2s in COPD.
IL-33 stimulates PBMC derived ILC2s in patients with $C O P D$. In response to rIL-33 stimulation, the number of ILC2s increased compared with the PBS control group, suggesting that rIL-33 stimulates the differentiation of peripheral blood ILC2s (Fig. 3A). There were significant differences between each group, but the $50 \mathrm{ng} / \mathrm{ml} \mathrm{IL-33} \mathrm{exhibited} \mathrm{the} \mathrm{strongest} \mathrm{differen-}$ tiation effect on ILC2 cells. To investigate the effects of rIL-33 and anti-ST-2 on the cell viability of ILC2s in vitro, a CCK- 8 assay was performed. As presented in Fig. 3B, the cell viability of ILC2s was significantly increased with 50 and $100 \mathrm{ng} / \mathrm{ml}$ of rIL-33 for $48 \mathrm{~h}$. However, this increase was abolished by simultaneous anti-ST-2 treatment. No obvious cell proliferation was observed in the PBS-treated group. Similarly, the levels of RORA, GATA3, ST2 and CRTH2 mRNA were significantly increased after stimulation with rIL-33 (Fig. 3C). This increase was blocked byanti-ST2 treatment. These results indicate that IL-33 increases the viability of ILC2s and it is likely that this effect is exerted, at least partially, via ST2. The current study also assessed the ability of ILC2 cells to secrete cytokines after stimulation with rIL-33. The results revealed that with the increase in the rIL-33 concentration, the secretion of IL-4, IL-5, IL-6 and IL-13 (Fig. 3D) increased significantly. However, the expression levels of these cytokines decreased significantly after the addition of ST2-neutralizing antibody. The results also 
A

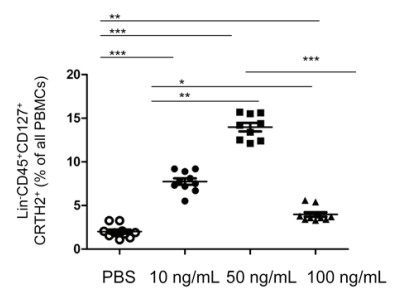

C

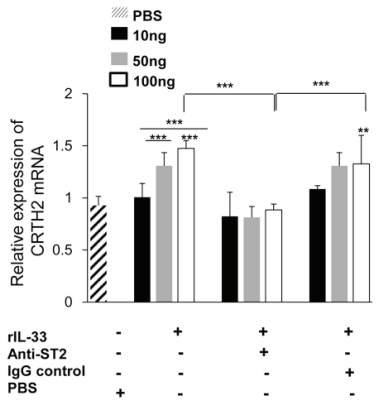

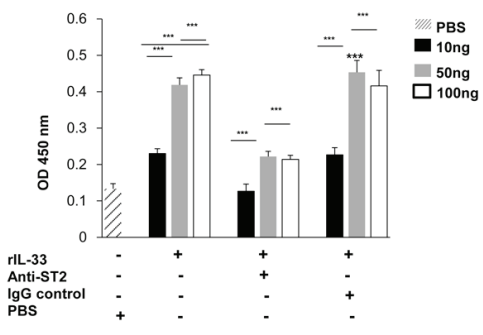

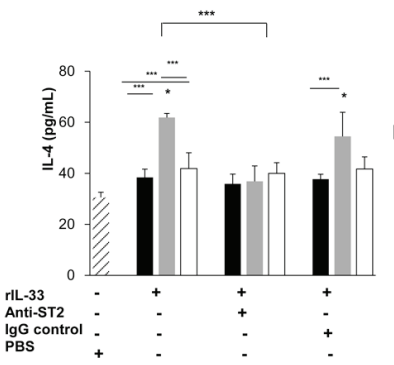

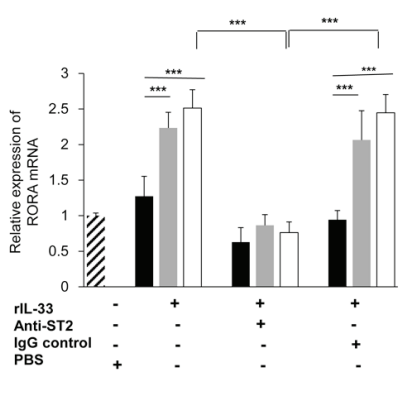
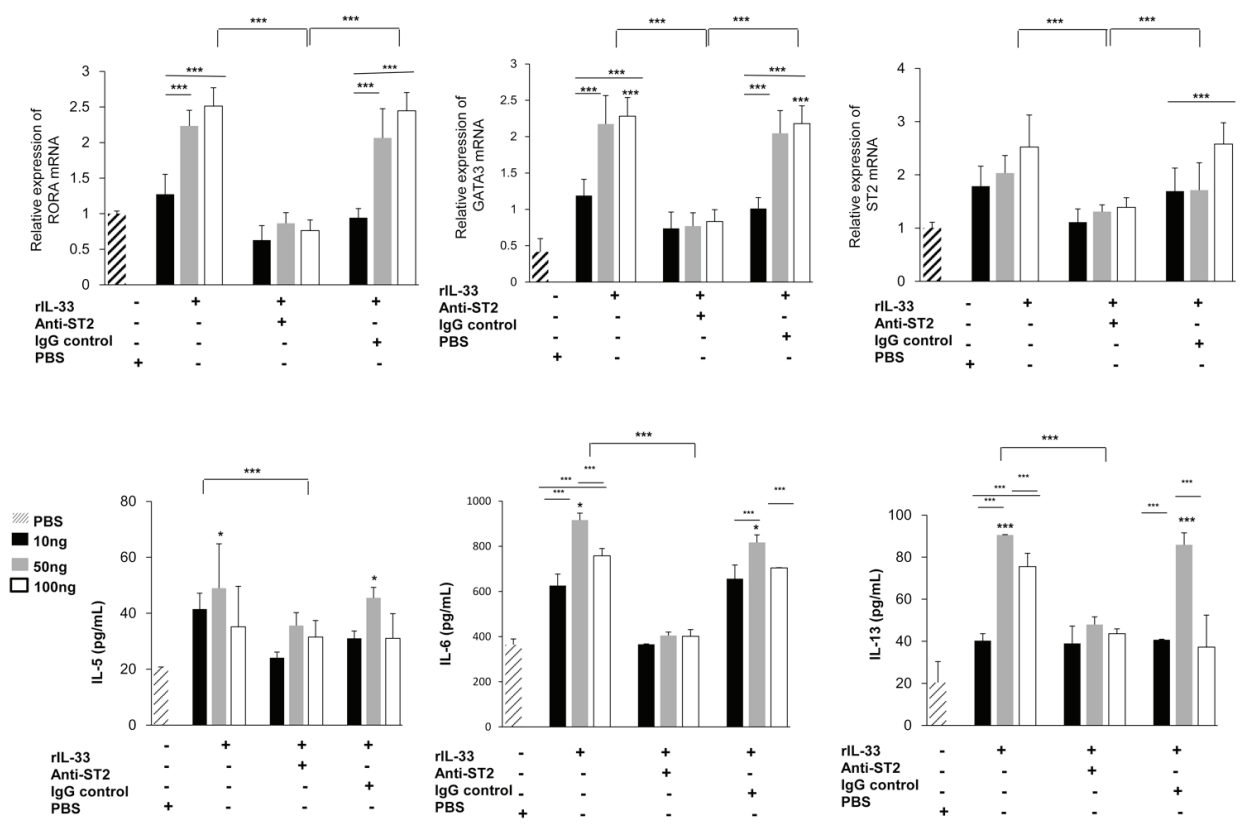

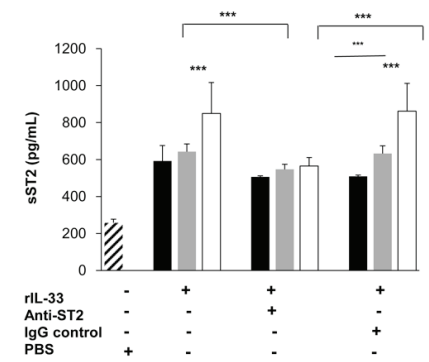

Figure 3. Viability of ILC2 cells and expression of cytokines after IL-33 stimulation. (A) The proportion of ILC2 cells in peripheral blood mononuclear cells from patients with COPD after stimulation with different concentrations of IL-33 for 48 h. (B) Cell viability was measured with a Cell Counting Kit-8 assay. The OD value at $450 \mathrm{~nm}$ is provided. (C and D) ILC2s from patients with COPD were stimulated with rIL-33, Anti-ST2, IgG control or PBS alone for $48 \mathrm{~h}$. (C) The relative expression of CRTH2, RORA, GATA3 and ST2 mRNA was detected by reverse transcription-quantitative PCR (n=10). (D) The supernatants were collected to detect changes in the levels of IL-4, IL-5, IL-6, IL-13 and sST2 ( $\mathrm{n}=10) .{ }^{*} \mathrm{P}<0.05,{ }^{* *} \mathrm{P}<0.01,{ }^{* * *} \mathrm{P}<0.001$ vs. PBS group. OD, optical density; rIL, recombinant interleukin; sST2, soluble ST2; COPD, chronic obstructive pulmonary disease; IgG, immunoglobulin G; GATA3, GATA binding protein 3; RORA, RAR-related orphan receptor $\alpha$; CRTH2, ST2 and prostaglandin D2 receptor 2.

indicated that, with the increase of the rIL-33 concentration, the level of sST-2 increased, which may attenuate the effect of IL-33 and cause the decrease of cytokines observed. Thus, the in vitro stimulation test further confirmed that IL-33 stimulates the differentiation of peripheral blood ILC2s in patients with COPD, and further induces ILC2s to produce the Th2 cytokines partially through the IL-33/ST2 signaling pathway, thus participating in the pathogenesis of COPD.

\section{Discussion}

Abnormal immune responses to environmental factors are considered to be the major cause of the pathogenesis of
COPD (28). There is increasing evidence that the response of the innate immune system is crucial for the development of COPD (16). IL-33 is a pleiotropic cytokine that may coordinate a series of complex immune responses in disease and the innate immune system $(29,30)$. IL-33 is thought to act as a pro-inflammatory factor and current research mostly focuses on its role in the cardiovascular system, autoimmune diseases, infectious diseases (8) and asthma (31,32). However, there is currently a lack of research on the role of IL-33 and ILC2 cells in COPD. The results of the present study indicate that the serum levels of IL-33 in COPD patients were significantly higher than those in healthy individuals. In addition, the expression of ST2 mRNA in PBMCs of COPD patients 
was significantly increased. IL-33 activates mitogen-activated protein kinase and $\mathrm{NF}-\kappa \mathrm{B}$ signaling pathways by binding to the receptors ST2 and IL-1RAcP, and promotes the expression of Th2 cell-associated cytokines, including IL-4, IL-5 and IL-13 (33). Similarly, the present study determined that the serum levels of IL-4, IL-6 and IL-13 in COPD patients were significantly higher than those in healthy individuals, suggesting that IL-33 may have a role in the pathogenesis of COPD through the ST2 signaling pathway.

ILC2s are a newly discovered type of innate immune cells characterized by the absence of lymphocyte markers and production of Th2-type cytokines, which may link innate immune responses and adaptive immune responses in diseases involving various Th2-type immune responses (34). The cells involved in the inflammatory response to COPD mainly include neutrophils, $\mathrm{CD}^{+} \mathrm{T}$ cells, $\mathrm{CD} 8^{+} \mathrm{T}$ cells, macrophages and dendritic cells (35). It has been indicated that ILC2 may also be involved in the pathogenesis of COPD (25). ILC2s that are already there, but in an inactive state, are activated by inflammatory mediators released by lung epithelial cells and other structural cells, as well as by immune cells, and promote the pathological inflammatory response in the lungs $(36,37)$. It has been reported that ILC2s express CRTH2 and promote the production of IL-13 after IL-33 stimulation (38). Furthermore, IL-33 promotes the egress of ILC2 cells from the bone marrow (39). These results suggest that human airway ILC2s may also respond to IL-33. Studies using mouse models have also indicated that IL-33 induces type 2 pneumonia by activating ILC2s $(40,41)$. Activation of ILC2s results in rapid and robust release of IL-4, IL-5 and IL-13, which are known to participate in airway eosinophilia, mucus production, airway hyper responsiveness and tissue remodeling (17). The results of the present study indicated that the peripheral blood ILC2s in patients with COPD were significantly elevated, and the mRNA expression levels of CRTH2 and RORA in PBMCs were significantly higher than those in healthy individuals. In addition, the flow cytometry results indicated that the proportion of ILC2 ST2 ${ }^{+}$cells in peripheral blood of patients with COPD was significantly higher than that of healthy individuals, suggesting that ILC2 cells may have a role in promoting the Th2-type immune response in COPD.

IL-33 stimulation of non-T, B cells in mice led to rapid production of Th2 cytokines (42). Therefore, IL-33 may cause Th2 cytokine production through Th2 cell-independent pathways involved in pathological processes. IL-33 is one of the major triggers of human ILC2 activation (43). In the present study, it was determined that IL-33 stimulated the proliferation and differentiation of ILC2s from patients with COPD in vitro, along with elevated mRNA expression of RORA, GATA3, ST2 and CRTH2 and upregulation of Th2 cytokines, including IL-4, IL-5, IL-6 and IL-13, leading to sustained inflammation and contributing to disease progression. sST2 is a decoy receptor regulating the activity of IL-33 (44). In the present study, $50 \mathrm{ng} / \mathrm{ml} \mathrm{IL-33} \mathrm{had} \mathrm{the} \mathrm{strongest} \mathrm{differentiation}$ effect on ILC2 cells. However, the dose effect of IL-33 on ILC2 cells still requires further study. Furthermore, the levels of sST2 increased as the IL-33 concentration increased. The increased sST2 may attenuate the effect of IL-33, thus causing the observed decrease in cytokine levels.

In the present study, according to GOLD staging, 5 patients with grade I pulmonary function, 94 with grade II pulmonary function and 8 patients with grade III pulmonary function were included. However, no patient with grade IV pulmonary function was included. As subgroup analysis may be incomplete without the group of patients with grade IV pulmonary function, no subgroup analysis was performed. A further study with a subgroup analysis is required.

In conclusion, IL-33 promotes the differentiation of ILC2s and the secretion of IL-4, IL-5 and IL-6 in PBMCs from patients with COPD. IL-33 and ILC2s may have important roles in the development of COPD. Further in-depth study of the mechanism of action of IL-33 and ILC2s cells in COPD is required. The present study may provide experimental evidence for the development of cell immunotherapy for COPD.

\section{Acknowledgements}

Not applicable.

\section{Funding}

The current study was supported by the National Natural Science Foundation Regional Fund Project (grant no. 81760793).

\section{Availability of data and materials}

The datasets used and/or analyzed during the present study are available from the corresponding author on reasonable request.

\section{Authors' contributions}

Conceived and designed the experiments: JD and FL. Performed the experiments: MJ, ST, SZ and FZ. Analyzed the data: JW. Wrote the manuscript: MJ, JD. All authors read and approved the final manuscript.

\section{Ethics approval and consent to participate}

The present study was approved by the Medical Ethics Committee of the Affiliated Hospital of Traditional Chinese Medicine, Xinjiang Medical University (Urumqi, China). In addition, written informed consent was obtained from each subject.

\section{Patient consent for publication}

Not applicable.

\section{Competing interests}

The authors declare that they have no competing interests.

\section{References}

1. Blanchette CM, Gross NJ and Altman P: Rising costs of COPD and the potential for maintenance therapy to slow the trend. Am Health Drug Benefits 7: 98-106, 2014.

2. Gupta D, Agarwal R, Aggarwal AN, Maturu VN, Dhooria S, Prasad KT, Sehgal IS, Yenge LB, Jindal A, Singh N, et al: Guidelines for diagnosis and management of chronic obstructive pulmonary disease: Joint ICS/NCCP (I) recommendations. Lung India 30: 228-267, 2013. 
3. Zhang Z, Cheng X, Yue L, Cui W, Zhou W, Gao J and Yao H: Molecular pathogenesis in chronic obstructive pulmonary disease and therapeutic potential by targeting AMP-activated protein kinase. J Cell Physiol 233: 1999-2006, 2018.

4. Kim SW, Rhee CK, Kim KU, Lee SH, Hwang HG, Kim YI, Kim DK, Lee SD, Oh YM and Yoon HK: Factors associated with plasma IL-33 levels in patients with chronic obstructive pulmonary disease. Int J Chron Obstruct Pulmon Dis 12: 395-402, 2017.

5. Hogg JC, Chu F, Utokaparch S, Woods R, Elliott WM, Buzatu L, Cherniack RM, Rogers RM, Sciurba FC, Coxson HO and Paré PD: The nature of small-airway obstruction in chronic obstructive pulmonary disease. New Engl J Med 350: 2645-2653, 2004.

6. Brusselle GG, Joos GF and Bracke KR: New insights into the immunology of chronic obstructive pulmonary disease. Lancet 378: 1015-1026, 2011.

7. Lee N, Shin MS and Kang I: T-cell biology in aging, with a focus on lung disease. J Gerontol A Biol Sci Med Sci 67: 254-263, 2012.

8. Molofsky AB, Savage AK and Locksley RM: Interleukin-33 in tissue homeostasis, injury, and inflammation. Immunity 42 : 1005-1019, 2015.

9. Gordon ED, Simpson LJ, Rios CL, Ringel L, Lachowicz-Scroggins ME, Peters MC, Wesolowska-Andersen A, Gonzalez JR, MacLeod HJ, Christian LS, et al: Alternative splicing of interleukin-33 and type 2 inflammation in asthma. Proc Natl Acad Sci USA 113: 8765-8770, 2016.

10. Nasr WF, Sorour SS, El Bahrawy AT, Boghdadi GS and El Shahaway AA: The role of the level of interleukin-33 in the therapeutic outcomes of immunotherapy in patients with allergic rhinitis. Int Arch Otorhinolaryngol 22: 152-156, 2018

11. Shan S, Li Y, Wang J, Lv Z, Yi D, Huang Q, Corrigan CJ, Wang W, Quangeng $Z$ and Ying S: Nasal administration of interleukin-33 induces airways angiogenesis and expression of multiple angiogenic factors in a murine asthma surrogate. Immunology 148 83-91, 2016.

12. Kearley J, Silver JS, Sanden C, Liu Z, Berlin AA, White N, Mori M, Pham TH, Ward CK, Criner GJ, et al: Cigarette smoke silences innate lymphoid cell function and facilitates an exacerbated type I interleukin-33-dependent response to infection. Immunity 42: 566-579, 2015

13. Xia J, Zhao J, Shang J, Li M, Zeng Z, Zhao J, Wang J, Xu Y and Xie J: Increased IL-33 expression in chronic obstructive pulmonary disease. Am J Physiol Lung Cell Mol Physiol 308: L619-L627, 2015.

14. Agapov E, Battaile JT, Tidwell R, Hachem R, Patterson GA, Pierce RA, Atkinson JJ and Holtzman MJ: Macrophage chitinase 1 stratifies chronic obstructive lung disease. Am J Respir Cell Mol Biol 41: 379-384, 2009.

15. Kim EY, Battaile JT, Patel AC, You Y, Agapov E, Grayson MH, Benoit LA, Byers DE, Alevy Y, Tucker J, et al: Persistent activation of an innate immune response translates respiratory viral infection into chronic lung disease. Nat Med 14: 633-640, 2008.

16. Shaykhiev R and Crystal RG: Innate immunity and chronic obstructive pulmonary disease: A mini-review. Gerontology 59: 481-489, 2013.

17. Karta MR, Broide DH and Doherty TA: Insights into group 2 innate lymphoid cells in human airway disease. Curr Allergy Asthma Rep 16: 8, 2016.

18. Moro K, Yamada T, Tanabe M, Takeuchi T, Ikawa T, Kawamoto H, Furusawa J, Ohtani M, Fujii H and Koyasu S: Innate production of $\mathrm{T}(\mathrm{H}) 2$ cytokines by adipose tissue-associated c-Kit $(+) \mathrm{Sca}-1(+)$ lymphoid cells. Nature 463: 540-544, 2010.

19. Neill DR, Wong SH, Bellosi A, Flynn RJ, Daly M, Langford TK, Bucks C, Kane CM, Fallon PG, Pannell R, et al: Nuocytes represent a new innate effector leukocyte that mediates type-2 immunity. Nature 464: 1367-1370, 2010

20. Price AE, Liang HE, Sullivan BM, Reinhardt RL, Eisley CJ, Erle DJ and Locksley RM: Systemically dispersed innate IL-13-expressing cells in type 2 immunity. Proc Natl Acad Sci USA 107: 11489-11494, 2010.

21. Wong SH, Walker JA, Jolin HE, Drynan LF, Hams E, Camelo A, Barlow JL, Neill DR, Panova V, Koch U, et al: Transcription factor ROR $\alpha$ is critical for nuocyte development. Nat Immunol 13: 229-236, 2012

22. Doherty TA: At the bench: Understanding group 2 innate lymphoid cells in disease. J Leukoc Biol 97: 455-467, 2015.

23. Huang Y and Paul WE: Inflammatory group 2 innate lymphoid cells. Int Immunol 28: 23-28, 2016.
24. Salimi M, Barlow JL, Saunders SP, Xue L, Gutowska-Owsiak D, Wang X, Huang LC, Johnson D, Scanlon ST, McKenzie AN, et al: A role for IL-25 and IL-33-driven type-2 innate lymphoid cells in atopic dermatitis. J Exp Med 210: 2939-2950, 2013.

25. De Grove KC, Provoost S, Verhamme FM, Bracke KR, Joos GF, Maes T and Brusselle GG: Characterization and quantification of innate lymphoid cell subsets in human lung. PLoS One 11: e0145961, 2016

26. Oczypok EA, Milutinovic PS, Alcorn JF, Khare A, Crum LT, Manni ML, Epperly MW, Pawluk AM, Ray A and Oury TD: Pulmonary receptor for advanced glycation end-products promotes asthma pathogenesis through IL-33 and accumulation of group 2 innate lymphoid cells. J Allergy Clin Immunol 136: 747-756.e4, 2015

27. Livak KJ and Schmittgen TD: Analysis of relative gene expression data using real-time quantitative PCR and the 2(-Delta Delta $\mathrm{C}(\mathrm{T})$ ) method. Methods 25: 402-408, 2001

28. Bhat TA, Panzica L, Kalathil SG and Thanavala Y: Immune dysfunction in patients with chronic obstructive pulmonary disease. Ann Am Thorac Soc 12 (Suppl 2): S169-S175, 2015.

29. Lefrançais E, Duval A, Mirey E, Roga S, Espinosa E, Cayrol C and Girard JP: Central domain of IL-33 is cleaved by mast cell proteases for potent activation of group-2 innate lymphoid cells. Proc Natl Acad Sci USA 111: 15502-15507, 2014.

30. Monticelli LA, Osborne LC, Noti M, Tran SV, Zaiss DM and Artis D: IL-33 promotes an innate immune pathway of intestinal tissue protection dependent on amphiregulin-EGFR interactions. Proc Natl Acad Sci USA 112: 10762-10767, 2015.

31. Mizutani N, Nabe T and Yoshino S: Interleukin-33 and alveolar macrophages contribute to the mechanisms underlying the exacerbation of IgE-mediated airway inflammation and remodelling in mice. Immunology 139: 205-218, 2013.

32. Smith D, Helgason H, Sulem P, Bjornsdottir US, Lim AC, Sveinbjornsson G, Hasegawa H, Brown M, Ketchem RR, Gavala M, et al: A rare IL33 loss-of-function mutation reduces blood eosinophil counts and protects from asthma. PLoS Genet 13: e1006659, 2017.

33. Xu H, Turnquist HR, Hoffman R and Billiar TR: Role of the IL-33-ST2 axis in sepsis. Mil Med Res 4: 3, 2017.

34. McKenzie AN: Type-2 innate lymphoid cells in asthma and allergy. Ann Am Thorac Soc 11 (Suppl 5): S263-S270, 2014

35. Mortaz E, Folkerts G and Redegeld F: Mast cells and COPD Pulm Pharmacol Ther 24: 367-372, 2011.

36. Mohapatra A, Van Dyken SJ, Schneider C, Nussbaum JC, Liang HE and Locksley RM: Group 2 innate lymphoid cells utilize the IRF4-IL-9 module to coordinate epithelial cell maintenance of lung homeostasis. Mucosal Immunol 9: 275-286, 2016.

37. Silver JS, Kearley J, Copenhaver AM, Sanden C, Mori M, Yu L, Pritchard GH, Berlin AA, Hunter CA, Bowler R, et al: Inflammatory triggers associated with exacerbations of COPD orchestrate plasticity of group 2 innate lymphoid cells in the lungs. Nat Immunol 17: 626-635, 2016.

38. Mjösberg JM, Trifari S, Crellin NK, Peters CP, van Drunen CM, Piet B, Fokkens WJ, Cupedo T and Spits H: Human IL-25- and IL-33-responsive type 2 innate lymphoid cells are defined by expression of CRTH2 and CD161. Nat Immunol 12: 1055-1062, 2011.

39. Stier MT, Zhang J, Goleniewska K, Cephus JY, Rusznak M, Wu L, Van Kaer L, Zhou B, Newcomb DC and Peebles RS Jr: IL-33 promotes the egress of group 2 innate lymphoid cells from the bone marrow. J Exp Med 215: 263-281, 2018.

40. Doherty TA, Khorram N, Chang JE, Kim HK, Rosenthal P, Croft $\mathrm{M}$ and Broide DH: STAT6 regulates natural helper cell proliferation during lung inflammation initiated by Alternaria. Am J Physiol Lung Cell Mol Physiol 303: L577-L588, 2012.

41. Riedel JH, Becker M, Kopp K, Düster M, Brix SR, Meyer-Schwesinger C, Kluth LA, Gnirck AC, Attar M, Krohn S, et al: IL-33-mediated expansion of type 2 innate lymphoid cells protects from progressive glomerulosclerosis. J Am Soc Nephrol 28: 2068-2080, 2017.

42. Furusawa J, Moro K, Motomura Y, Okamoto K, Zhu J, Takayanagi $\mathrm{H}$, Kubo $\mathrm{M}$ and Koyasu S: Critical role of p38 and GATA3 in natural helper cell function. J Immunol 191: 1818-1826, 2013

43. Chang J, Xia YF, Zhang MZ and Zhang LM: IL-33 signaling in lung injury. Transl Perioper Pain Med 1: 24-32, 2016.

44. Hayakawa H, Hayakawa M and Tominaga SI: Soluble ST2 suppresses the effect of interleukin-33 on lung type 2 innate lymphoid cells. Biochem Biophys Rep 5: 401-407, 2016. 